\title{
TERRITÓRIOS DE SAÚDE E PINTURA: PINCELADAS PICTÓRICAS E SOCIOCULTURAIS
}

\author{
Nádile Juliane Costa de Castro' ${ }^{1}$
}

RECEBIDO: $16 / 08 / 2018$ | 21/08/2018

DOI: $10.5902 / 2317175834313$

\section{RESUMO}

A pintura vem sendo utilizada como instrumento para representar instituições, seus valores, comportamentos e sumariamente estabelecer relações sociais por meio de representações pictóricas nas últimas décadas. É um fenômeno que vem a representar pela sensibilidade das cores e das artes, assim como de seus processos construtivos às faces invisíveis de povos e populações vulneráveis. O objetivo deste trabalho é divulgar o imagético dos povos indígenas das etnias do baixo amazonas por meio de arquivos de registros de pesquisa de campo em formato pictórico por meio da pintura. $\mathrm{O}$ trabalho utiliza a técnica de pintura de retrato e tem como base a pintura à óleo. É um conjunto de retratos que mostram a diversidade e simbologias da cultura indígena, por meio de expressões registradas in loco, realizadas entre os anos de 2015 a 2018 no município de Oriximiná, PA, onde há exploração de mineração por empreendimentos capitalistas. Foi possível, não somente entrar no universo de expressão corporal das etnias registradas, mas também, identificar novos e antigos costumes inseridos, possibilitando uma reflexão sobre populações tradicionais e desenvolvimento por uma ótica visual e social.

Palavras-chave: pintura; saúde coletiva; populações vulneráveis; cultura

\footnotetext{
1 Doutoranda em Ciências socioambientais pelo Núcleo de Altos Estudos Amazônicos da UFPA. Mestre em doenças tropicais pelo Núcleo de Medicina Tropical/UFPA. Especialista em saúde Pública. Enfermeira. Pesquisa sobre saúde de populações tradicionais, educação em saúde e vigilância sanitária. Atuou no DSEI GUATOC e CTA de Benevides-PA. Já foi docente da UFPA, UEPA, FCAR Estácio e UNAMA. Participa atualmente do Grupo LabCorpo e Grupo de pesquisa das Guianas.
} 


\section{Introdução}

Os formatos dentro da arte visual hoje possuem vasto campo de possibilidades quanto os processos interdisciplinares em que são construídos os processos criativos. Seus resultados revelam a interligação com várias áreas, inclusive muito efetiva na área de ciências humanas e sociais. Nestes termos, é relevante estudar os vários fenômenos paralelos a esse constructo, pois representam simbologias de grupos, movimentos e indivíduos. Contudo, entendese que sua base principal é a arte plástica, e justamente por isso, que apesar de novas vertentes a serem observadas, há também antigas linhas de criação que vêm ganhando novos conceitos.

Considerando todos estes fatos, não há movimento mais fidedigno que a pintura quanto a esses aspectos, pois, tem conseguido se manter ao longo dos séculos paralelamente ao aparecimento de novas tecnologias de registro de imagens, e inclusive dos fenômenos sociais e econômicos ocorridos no último século. Ademais, seu processo de construção sofreu pequenas intervenções no que diz do uso de seus instrumentos de apoio, como por exemplo a fotografia digital, que é usada como aporte em alguns casos, como na captura de retratos para conceitos contemporâneos. Contudo, o seu processo pictórico, em geral, continua muito fidedigno ao longo dos anos.

Para entendimento dessa afirmativa é preciso entender que para que uma pintura chegue em seu processo final, primeiramente ela passa por um caminho que reflete o próprio estudo do pintor, e por isso, pode conter acertos e erros, assim como avanços, retrocessos e abandono da obra. Esses fatos poderão ser realizados em tempos diferentes, realizando articulações entre si, assim como revelando novas abordagens e novas descobertas. Perceber-se, portanto, que o estudo da pintura é uma constante aceitação de que haja possibilidades de riscos durante sua execução (MORAES, 2015)

Nessa lógica, a pintura, assim como outras formas de expressão artísticas foram sendo mescladas por outros movimentos das artes. Esta vem realizando transformações no cenário artísticos e gerando diversos questionamentos sobre a representação artística e até sobre a definição da arte (BRITTO, 2014). $\mathrm{Na}$ continuidade destes delineamentos é válido referenciar que a pintura vem sendo também utilizada como instrumento para representar instituições, seus valores, comportamentos e sumariamente estabelecer relações sociais por meio de representações das relações em sociedade (CHAVES, 2016).

Assim sendo, o objetivo deste trabalho é divulgar a faces dos povos indígenas das etnias do baixo amazonas por meio de arquivos de registros de pesquisa de campo em formato pictórico, por meio da pintura. É um projeto paralelo a pesquisa de campo de uma tese na área de ciências socioambientais e por tal, vem a buscar novos campos para a reflexão dos movimentos sociais e populações vulneráveis de modo a diminuir a invisibilidade social destes. 


\section{Breves apontamentos sobre a experiência}

As pinturas em formato retrato constituem importantes registros de grupos, famílias e populações e é um formato visual que atravessou gerações e está cada vez mais presente nas manifestações artísticas contemporâneas. A pintura também possui um engajamento social embutido em suas pinceladas, podendo ser utilizado como ferramenta para reflexão de fenômenos sociais. Considerados essas assertivas o objetivo deste trabalho é divulgar o imagético dos povos indígenas das etnias do baixo amazonas por meio de arquivos de registros de campo em formato pictórico.

O trabalho utiliza a técnica de pintura de retrato e tem como base a pintura à óleo, e mantém a paleta de cores observada no registro. É um conjunto de retrato em andamento que mostra a diversidade e simbologias da cultura indígena, por meio de expressões registradas in loco no território de uma casa de saúde indígena do Distrito de Saúde Especial Indígena (DSEI Guamá-Tocantins), realizadas entre os anos de 2015 e 2018 no município de Oriximiná, PA, onde se encontram 21 etnias. Foram conservadas as pinturas corporais realizadas com corantes naturais, sendo observada em alguns retratos de modo simbólico.

As etnias registradas estão localizadas no município de Oriximiná que localizado no baixo amazonas no estado do Pará, e desde o final da década 1970 vem sendo explorado por empreendimentos capitalistas pela extração de bauxita. Os atuais platôs de exploração mineral e de interesse vem alcançado terras em que envolvem populações tradicionais como remanescentes quilombolas e povos indígenas. Essa configuração vem causando diversos alertas quanto a questões ambientais e culturais. Ademais, considerando que esses fenômenos cooptam estes povos e populações da região, este registro também estimula refletir sobre as intervenções em suas culturas. Assim sendo, é oportuno utilizar registros e processos criativos que despertem a consciência social quanto a esse tema.

Com este trabalho é possível não somente entrar no universo de expressão corporal das etnias registradas, mas identificar novas e antigas costumes inseridos, possibilitando uma reflexão sobre populações tradicionais e desenvolvimento por uma ótica visual e social pelo processo criativo (Figura 1). Nestes termos, alguns dos desenhos de base e das pinturas finalizadas apresentam indumentárias inseridas no contexto destes povos (Figura 2), mas também, simbologias corporais de luta, como no caso das pinturas corporais (Figura 3, 4). Assim como posições corporais que representam afeto e proteção, como da imagem em que há a relação mãe-filho (Figura ). 
TERRITÓRIOS DE SAÚDE E PINTURA: PINCELADAS PICTÓRICAS E SOCIOCULTURAIS

Figura 1 : Processo criativo Fonte: Acervo pessoal

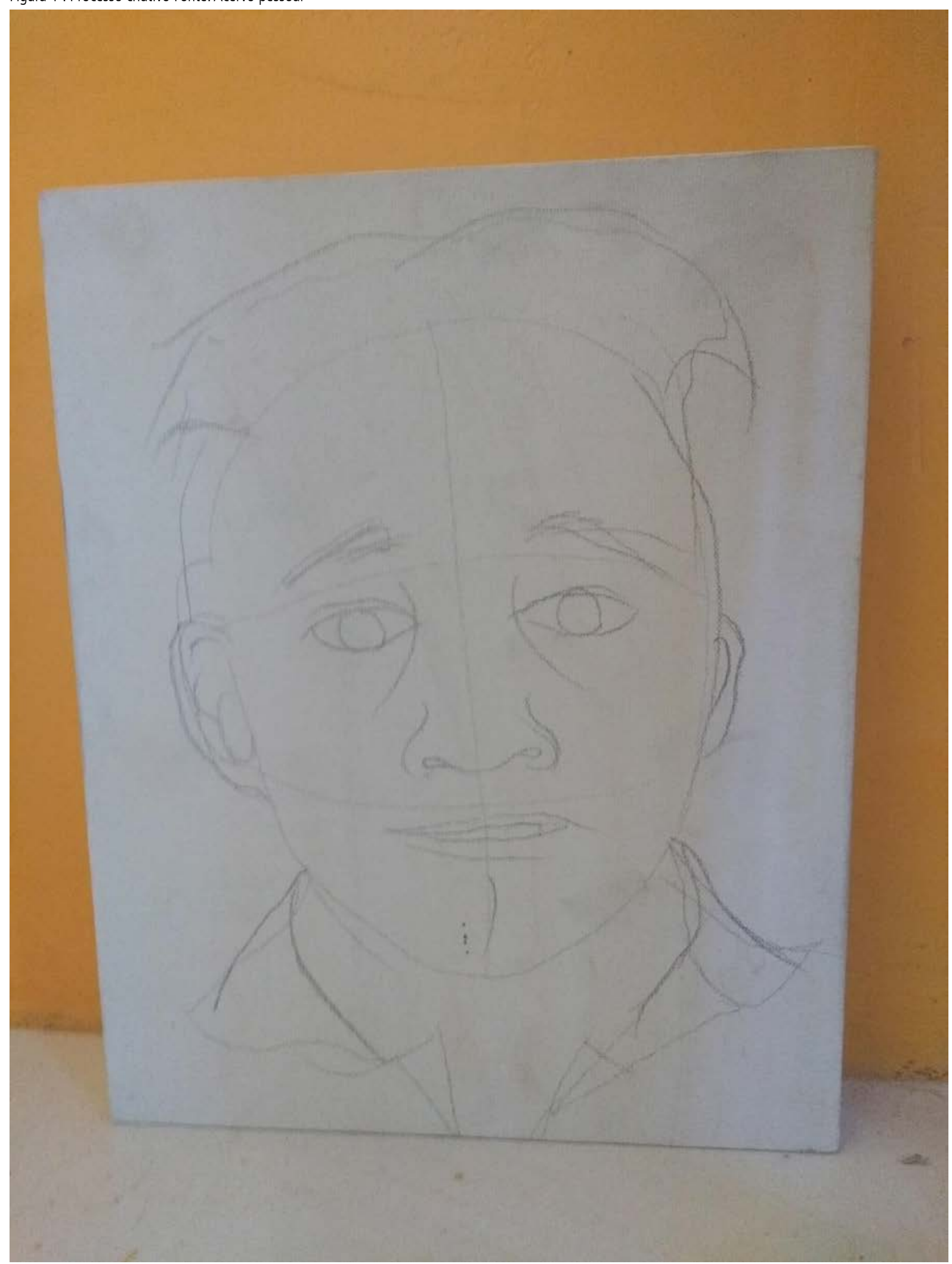

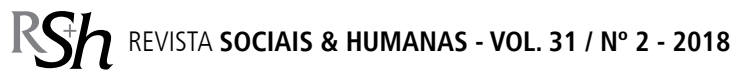




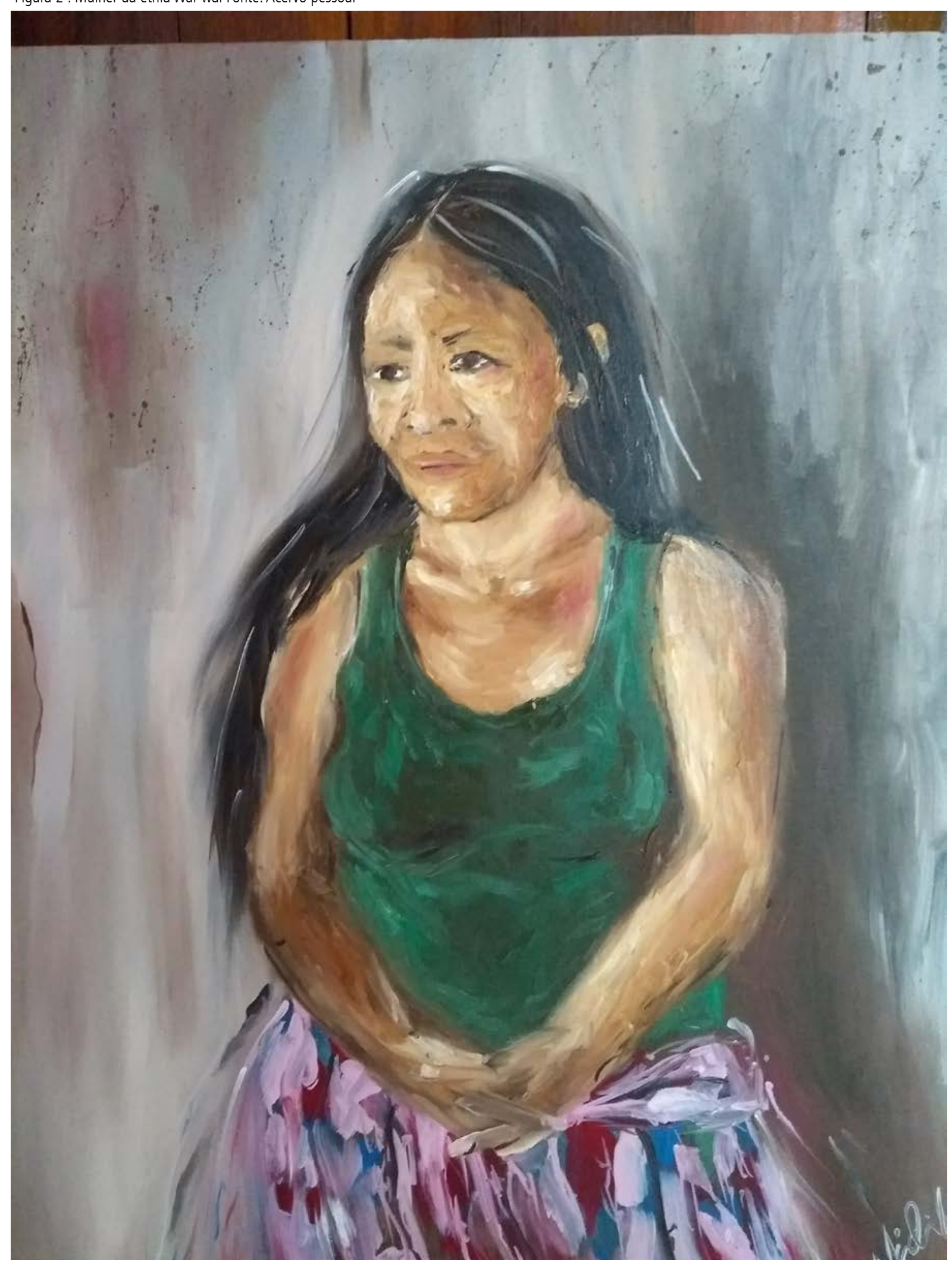


TERRITÓRIOS DE SAÚDE E PINTURA: PINCELADAS PICTÓRICAS E SOCIOCULTURAIS

Figura 3: Rascunho com referências de pinturas corporais

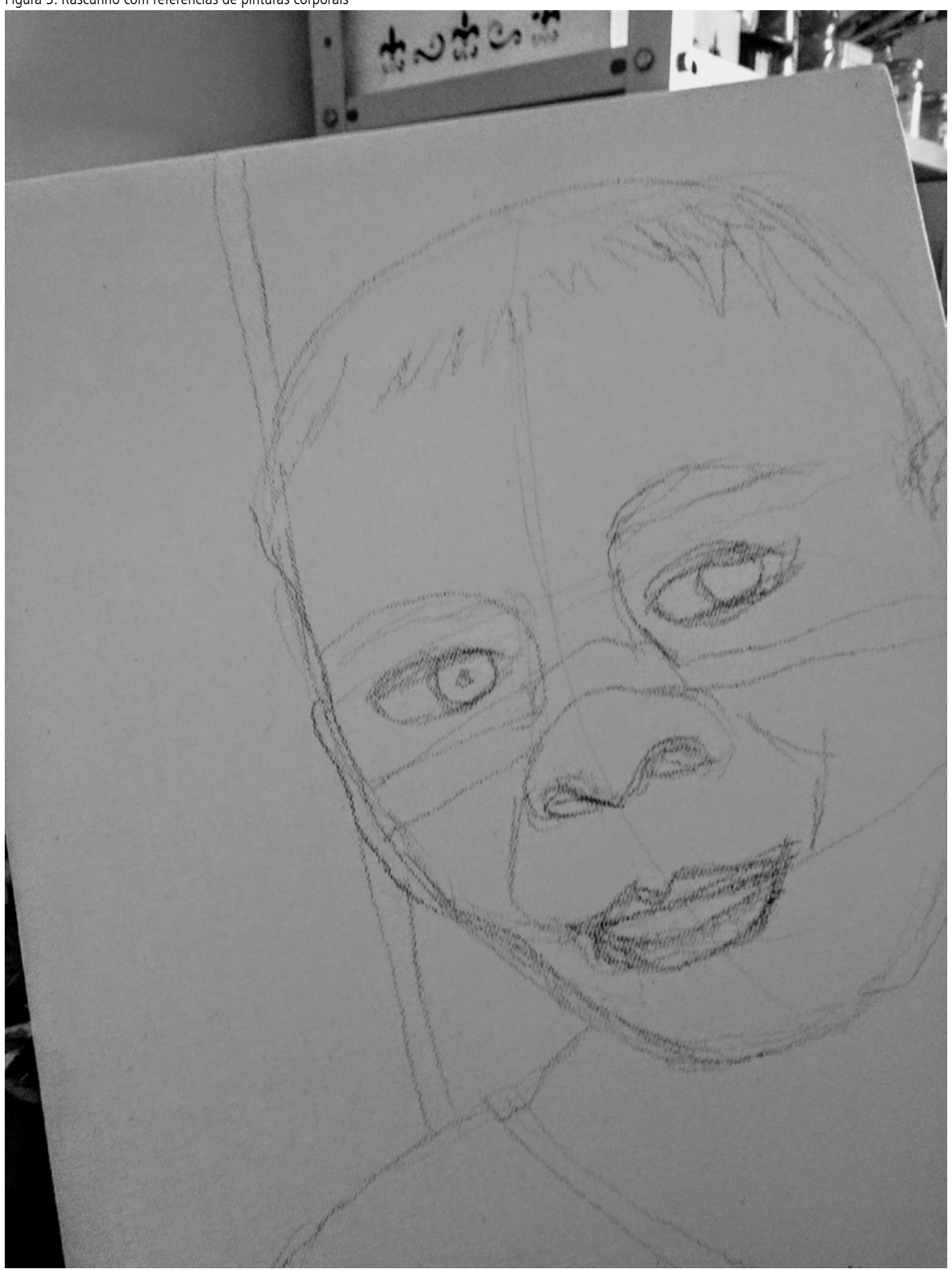

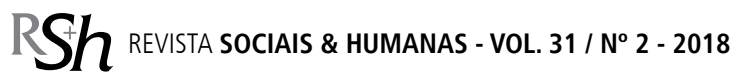




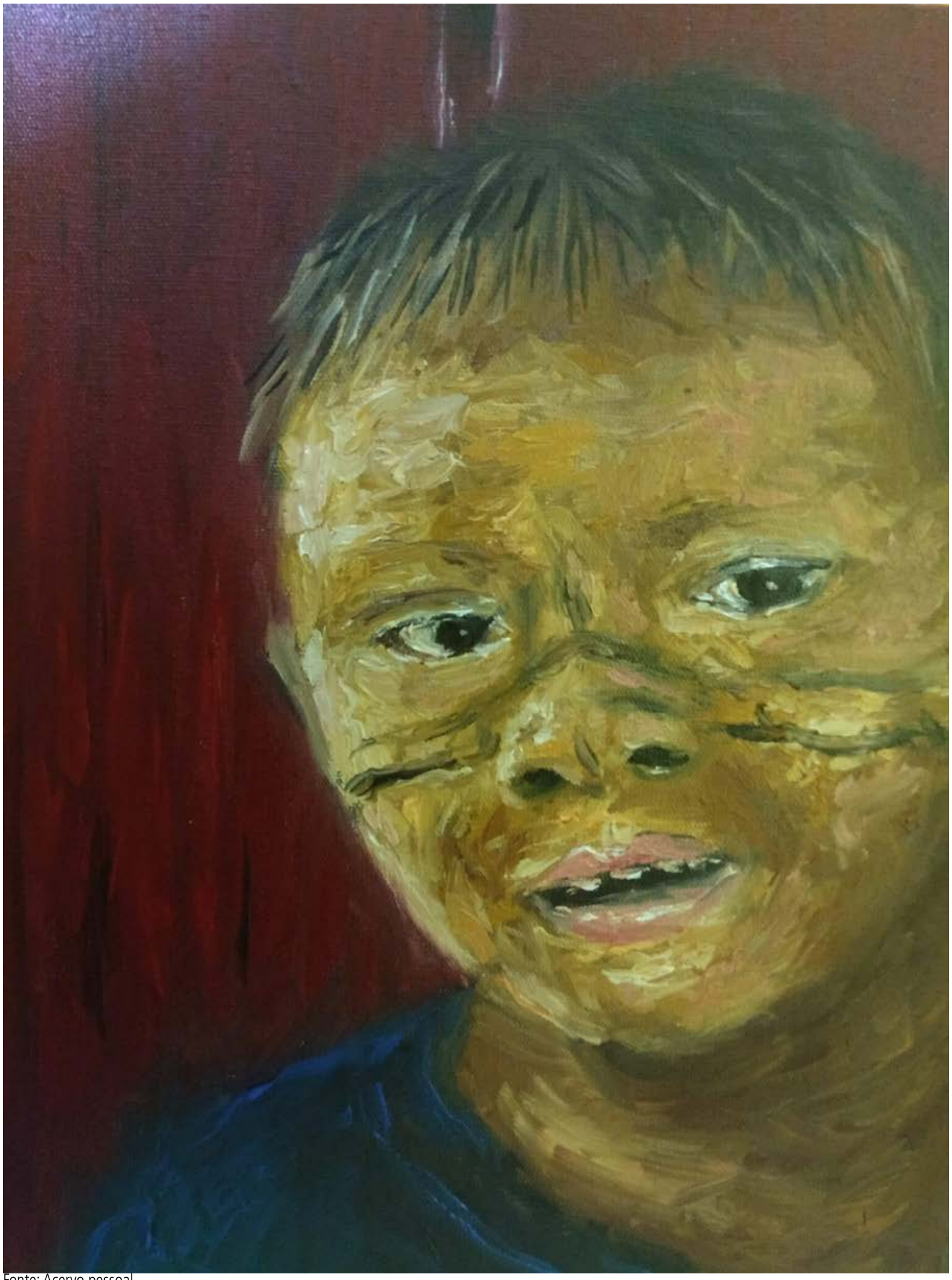


TERRITÓRIOS DE SAÚDE E PINTURA: PINCELADAS PICTÓRICAS E SOCIOCULTURAIS

Figura 5: Mãe-filho,Fonte: Acervo pessoal

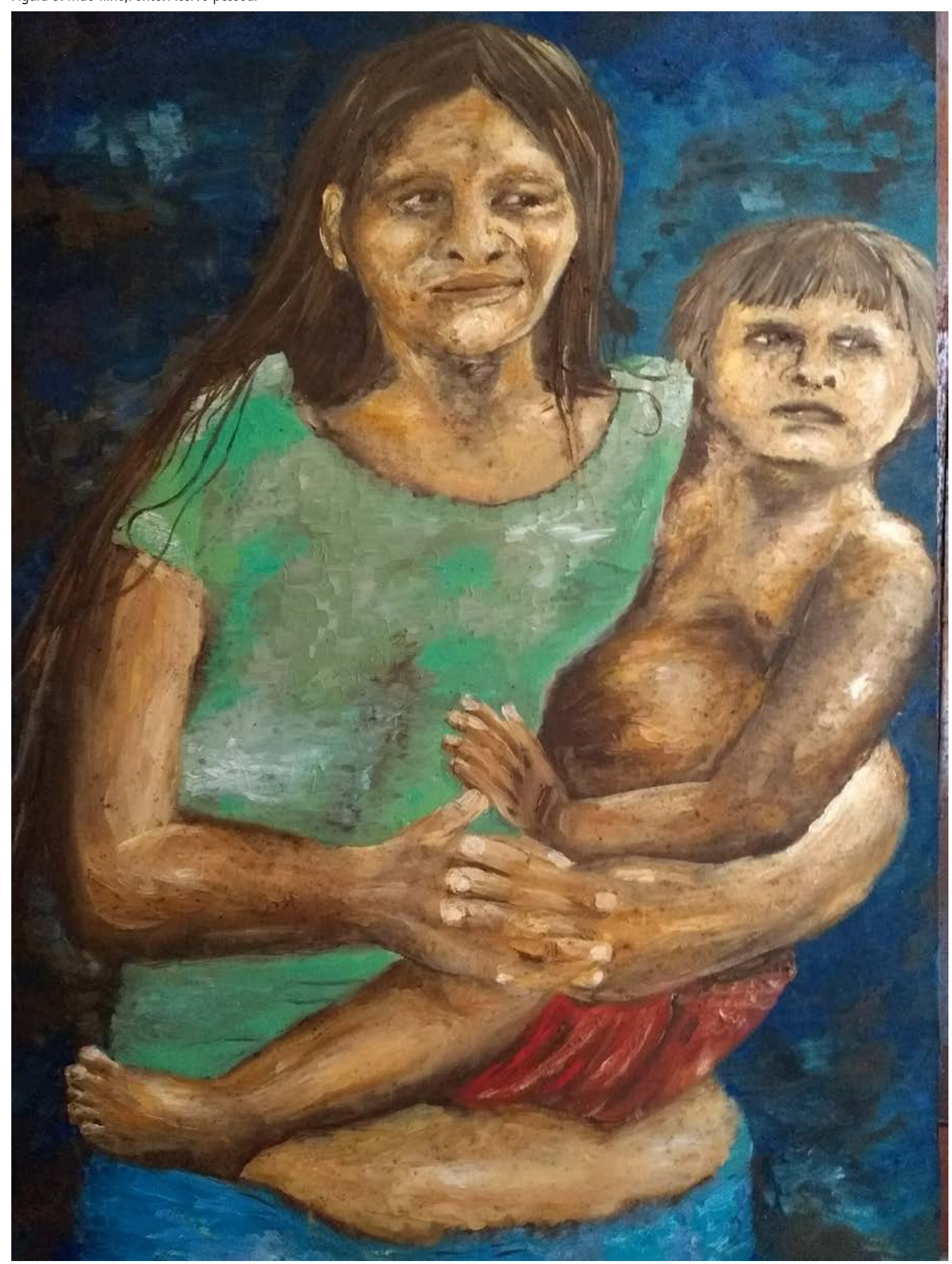

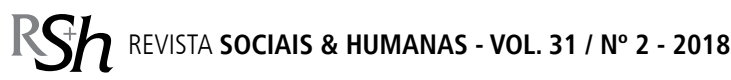




\section{Considerações Finais}

A amplitude das artes visuais para as questões étnicas e da biodiversidade é sempre possível e é parte dos processos criativos da contemporaneidade. No caso da pintura sua dinâmica é constante, e não se perdeu pelas novas tecnologias inseridas. Em verdade, ocorre em paralelo como os fenômenos contemporâneos, e por tal, quando unida pelas várias vertentes que a contemplam, alcançam vários campos de pesquisa e estudos.

Assim sendo, possibilita por meio da prática enveredar-se por meios que ante fora esquecido socialmente, virando objeto de reflexão. A pintura é uma ferramenta que pode agregar-se a pesquisas de campo de diversas áreas, contribuindo para que a mesma não se restrinja a apenas um campo de atuação, mas também é um objeto para comparação da ação do tempo e entidades.

\section{Referências}

BRITTO, L. O ensino de Artes Visuais contemporâneas para crianças de pré-escola. Revista Ciclos, v. 1, n. 2, p. 66-77, 2014.

CHAVES, L. P. Pintura e sociedade: retratos de beneméritos das Sociedades Portuguesas de Beneficência e o patrimônio cultural no Sul do Brasil. Revista Memória em Rede, v. 6, n. 10, p. 151-163, 2016

MORAES, D. A. Algumas considerações sobre o desenvolvimento do estudo da pintura do retrato. APOTHEKE, v. 1, n. 1, 2015. 